\title{
Isoniazid or rifampicin preventive therapy with and without screening for subclinical TB: a modeling analysis
}

Emily A. Kendall ${ }^{*}$ (D, Hamidah Hussain ${ }^{2}$, Amber Kunkel ${ }^{3}$, Rachel W. Kubiak ${ }^{4}$, Anete Trajman ${ }^{5}$, Richard Menzies ${ }^{6}$ and Paul K. Drain ${ }^{7}$

\begin{abstract}
Background: Short-course, rifamycin-based regimens could facilitate scale-up of tuberculosis preventive therapy (TPT), but it is unclear how stringently tuberculosis (TB) disease should be ruled out before TPT use.

Methods: We developed a state-transition model of a TPT intervention among two TPT-eligible cohorts: adults newly diagnosed with HIV in South Africa (PWH) and TB household contacts in Pakistan (HHCs). We modeled two TPT regimens -4 months of rifampicin [4R] or 6 months of isoniazid [6H] — comparing each to a reference of no intervention. Before initiating TPT, TB disease was excluded either through symptom-only screening or with additional radiographic screening that could detect subclinical TB but might limit access to the TPT intervention. TPT's potential curative effects on both latent and subclinical TB were modeled, as were both acquisitions of resistance and prevention of drug-resistant disease. Although all eligible individuals received the screening and/or TPT interventions, the modeled TB outcomes comprised only those with latent or subclinical TB that would have progressed to symptomatic disease if untreated.

Results: When prescribed after only symptom-based TB screening (such that individuals with subclinical TB were included among TPT recipients), 4R averted 45 active (i.e., symptomatic) TB cases (95\% uncertainty range 24-79 cases or 40-89\% of progressions to active TB) per 1000 PWH [17 (9-29, 43-94\%) per 1000 HHCs]; 6H averted 37 (19-66, 52-73\%) active TB cases among PWH [13 (7-23, 53-75\%) among HHCs]. With this symptom-only screening, for each net rifampicin resistance case added by 4R, 12 (3-102) active TB cases were averted among PWH (37 [9580] among HHCs); isoniazid-resistant TB was also reduced. Similarly, $6 \mathrm{H}$ after symptom-only screening increased isoniazid resistance while reducing overall and rifampicin-resistant active TB. Screening for subclinical TB before TPT eliminated this net increase in resistance to the TPT drug; however, if the screening requirement reduced TPT access by more than 10\% (the estimated threshold for 4R among HHCs) to 30\% (for 6H among PWH), it was likely to reduce the intervention's overall TB prevention impact.
\end{abstract}

\footnotetext{
* Correspondence: ekendall@jhmi.edu

'Division of Infectious Diseases and Center for Tuberculosis Research, Johns

Hopkins University School of Medicine, 1550 Orleans Street, Baltimore,

Maryland 21287, USA

Full list of author information is available at the end of the article
}

(c) The Author(s). 2021 Open Access This article is licensed under a Creative Commons Attribution 4.0 International License, which permits use, sharing, adaptation, distribution and reproduction in any medium or format, as long as you give appropriate credit to the original author(s) and the source, provide a link to the Creative Commons licence, and indicate if changes were made. The images or other third party material in this article are included in the article's Creative Commons licence, unless indicated otherwise in a credit line to the material. If material is not included in the article's Creative Commons licence and your intended use is not permitted by statutory regulation or exceeds the permitted use, you will need to obtain permission directly from the copyright holder. To view a copy of this licence, visit http://creativecommons.org/licenses/by/4.0/ The Creative Commons Public Domain Dedication waiver (http://creativecommons.org/publicdomain/zero/1.0/) applies to the data made available in this article, unless otherwise stated in a credit line to the data. 
Conclusions: All modeled TPT strategies prevent TB relative to no intervention, and differences between TPT regimens or between screening approaches are small relative to uncertainty in the outcomes of any given strategy. If most TPTeligible individuals can be screened for subclinical TB, then pairing such screening with rifamycin-based TPT maximizes active TB prevention and does not increase rifampicin resistance. Where subclinical TB cannot be routinely excluded without substantially reducing TPT access, the choice of TPT regimen requires weighing 4R's efficacy advantages (as well as its greater safety and shorter duration that we did not directly model) against the consequences of rifampicin resistance in a small fraction of recipients.

Keywords: Tuberculosis infection, Subclinical tuberculosis, Preventive therapy, Screening, Chest radiography, Global health, Antimicrobial resistance

\section{Background}

Tuberculosis (TB) preventive therapy (TPT) reduces TB incidence and mortality $[1,2]$ and is considered an essential tool for ending the TB pandemic [3-5]. Short-course TPT regimens could improve the global implementation and effectiveness of TPT [6]. Isoniazid for at least 6 months $(6 \mathrm{H})$ has long been standard, but shorter, rifamycin-based regimensincluding 4 months of daily rifampicin (4R) or 3 months of weekly rifapentine and isoniazid (3HP) - are efficacious, better tolerated, and more cost-effective [7-10] and have been included in recent TB prevention guidelines [11, 12].

TPT has not been observed to cause clinically significant increases in drug resistance [13, 14], but the available data come from studies that rigorously excluded TB disease before prescribing TPT. Thus, concern about the potential consequences of inadvertent monotherapy remains a barrier to access to TPT in general [15], and to rifamycin-based TPT in particular given the importance of rifamycins in the treatment of active TB [16, 17]. Requirements that TB disease be excluded with sensitive radiographic or bacteriologic testing before TPT may, however, limit access [18-20]. Recognizing this, WHO guidance only conditionally recommends chest radiographic screening for TPT-eligible adult contacts and offers it as an option for people living with HIV (PWH) who are receiving antiretroviral therapy; guideline advise that decisions be guided by "local epidemiology, health infrastructure, and resources" [11].

The relevant tradeoffs between sensitively excluding TB disease and maximizing TPT access have not been quantified in a way that can guide clinicians and program managers, nor have they compared between isoniazid- and rifamycin-based TPT regimens. To address this need, we developed a decision analytic model of TB screening and TPT in two populations for whom TPT is recommended [11]: PWH and household contacts (HHCs). We compared outcomes after symptom-only TB screening and after radiographic screening (with, potentially, a reduction in TPT access when radiography was required) for two TPT regimens: 6 months of isoniazid $(6 \mathrm{H}$, still the most widely used regimen globally [21]) and $4 \mathrm{R}$ (the regimen with the greatest potential for acquired rifampicin resistance, and also a conservative proxy for 3HP).

\section{Methods}

\section{TPT simulation model}

We constructed state-transition models of a PWH cohort of 1000 adults newly diagnosed with HIV and initiating antiretroviral therapy (ART) and a HHC cohort of 1000 all-age household contacts $[22,23]$ of recently diagnosed drug-susceptible TB index patients. Each cohort was stratified by TB state, drug susceptibility (pan-susceptible, isoniazid monoresistant, rifampicin monoresistant, or multidrug [isoniazid and rifampicin] resistant), and either CD4 count (for PWH) or age (for HHCs). TB states included active disease (symptomatic), subclinical progressors (currently asymptomatic but microbiologically or radiographically detectable, and on a course that would progress to active if untreated), latent progressors (with infections that would progress to active disease at some time in the future), and those who would never progress to active disease. We modeled an intervention of TPT (4R or $6 \mathrm{H})$ with or without a test to first exclude subclinical TB).

To focus on outcomes that TPT could affect, we simulated two distinct subgroups in progressive TB states within each cohort, illustrated in Fig. 1:

1) "Latent progressors," with $M$. tuberculosis infection but no current active TB disease, whose infections would, in absence of TPT, eventually progress to active disease;

2) "Subclinical progressors" with TB disease that was undetectable by a symptom screen but was microbiologically active (e.g., culture-positive) and would progress to symptoms (i.e., to active disease) if untreated.

Additional individuals with latent infections that would never progress to active disease, or with a prevalent subclinical disease that would resolve even without intervention, were not included in these "progressor" subgroups.

For these subgroups, we simulated the following steps (Fig. 1):

1. Symptom screening: At the time of contact investigation or antiretroviral therapy initiation, all 

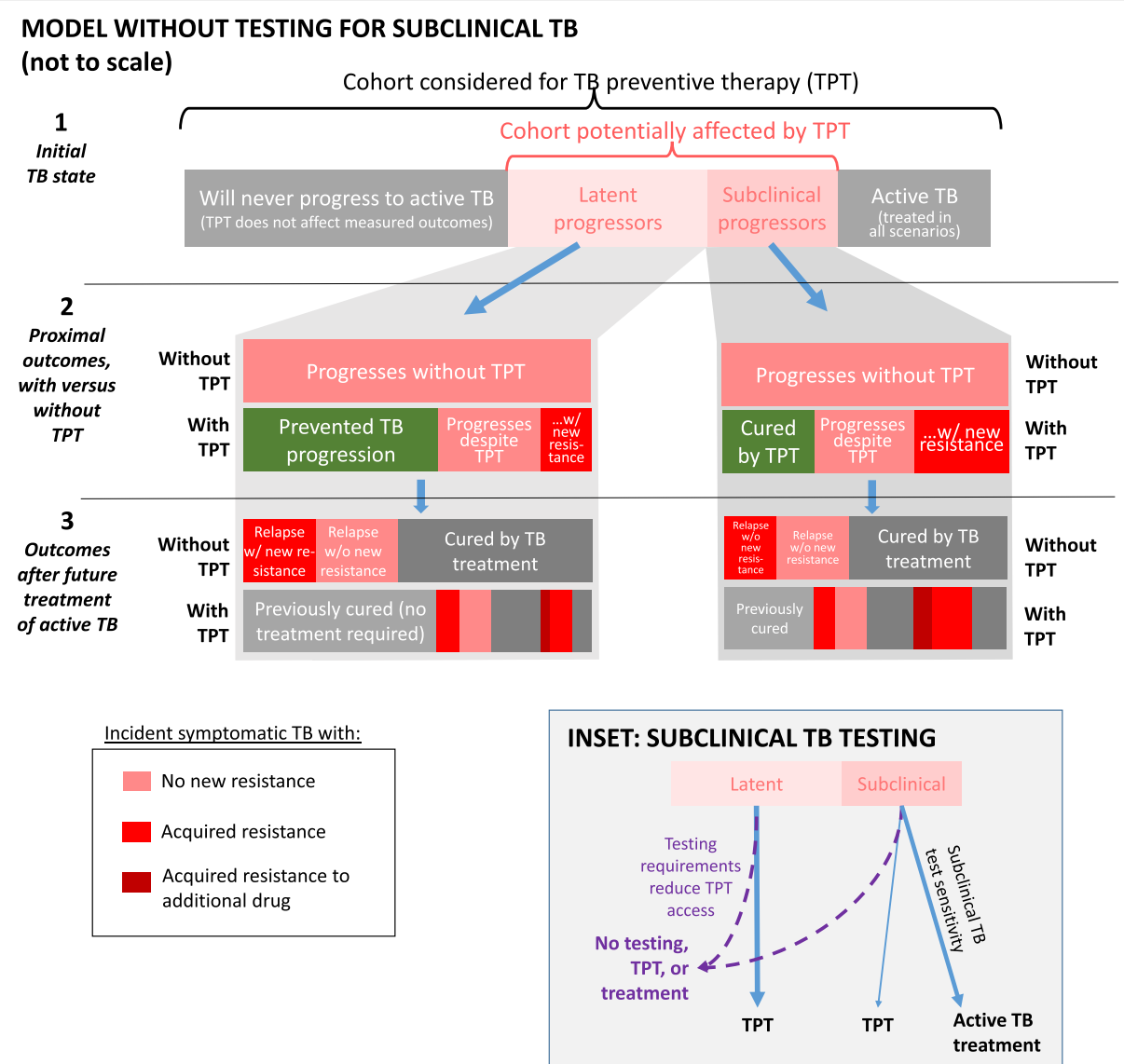

Fig. 1 Conceptual overview of the model, without screening for subclinical TB (main panel) and with screening (inset). Within each cohort, we identify two subgroups whose outcomes may be affected by TPT: those with a latent infection that will, if untreated, progress to active TB at some point in the future ("latent progressors"), and those who have prevalent subclinical TB (asymptomatic but detectable through additional testing such as chest X-ray or sputum testing) that will progress to active rather than resolving spontaneously ("subclinical progressors"). These subgroups are further stratified (not shown) by the drug resistance present at $t=0$ and by CD4 count (people living with HIV) or age (household contacts). These latent and subclinical progressor groups are followed through the following steps: (1) testing to detect and treat subclinical TB in some modeled scenarios [inset], (2) TPT (if given), and (3) TB treatment (if subclinical TB is diagnosed, or if progression to active TB occurs despite the intervention). For the TPT and treatment steps, the probabilities of cure, and of acquiring new or additional resistance if not cured, depend on the regimen and the drug resistance present. When testing for subclinical TB is required prior to TPT (Inset), it reduces access (such that a proportion of individuals with latent and subclinical TB receive neither the additional testing nor TPT), but a proportion of the remaining individuals with subclinical TB are identified and immediately treated for active TB. Proportions in the figure are not to scale. All modeled scenarios include symptom screening to detect and treat active TB, so the outcomes of those with active (symptomatic) TB at enrollment are not compared between scenarios

individuals were screened for active (i.e., symptomatic) TB disease. (Those who had a positive symptom screen and were confirmed to have active TB disease were assumed to receive treatment under all scenarios and were not modeled further.)

2. Possible additional screening (Fig. 1 inset): For individuals without symptoms, either (a) all were offered TPT or (b) they underwent an additional screening test such as chest radiography (assumed 90\% sensitive for all subclinical TB, regardless of whether it would progress if untreated). Such screening, if required, could be unavailable to a proportion of the cohort (20\% in primary analysis), who was then not eligible for TPT.

3. TPT for individuals not diagnosed with TB disease (Fig. 1, section 2): If latent progressors or subclinical progressors received TPT, they could be cured (more likely for latent than for subclinical TB) or they could progress to active disease with or without acquisition of resistance. TPT was assumed to have no effect if pre-existing resistance to the TPT drug was present.

4. Treatment of TB disease when indicated (Fig. 1, section 3): For subclinical progressors who were diagnosed and treated at the time of TPT 
consideration, and also for individuals who progressed from latent or subclinical to active TB in the future and were treated at that later time, we modeled the outcomes of TB treatment (Additional file 1: Table S4 [24-32]). Treatment failures and relapses were counted as active TB episodes when estimating the impact of TPT interventions on future TB incidence and drug resistance. Thus, we captured TPT's downstream effects on active TB incidence and drug resistance outcomes through the prevention of TB episodes whose treatment may have otherwise resulted in failure, relapse, or acquired resistance. Individuals with subclinical TB that would have resolved without intervention were not modeled as being at risk for treatment failure or relapse, even if they were treated.

\section{Parameter estimation}

\section{Cohort composition}

Key model parameters are shown in Table 1, with a full description in Additional file 1: Supplemental Methods $[7,8,13,21,24-74]$.

Primary clinical data, together with published systematic reviews, were used to estimate the number of latent progressors and subclinical progressors (i.e., people with TB infections or asymptomatic disease, respectively, that would later progress to active disease) within each cohort (Additional file 1: Supplemental Methods 1).

The PWH cohort is based on primary data from adults presenting for outpatient HIV testing in Kwa-Zulu Natal, South Africa, from September 2013 through February 2019 [75]. Enrollees were screened for TB based on symptoms, then followed for 12 months for incident TB. Patients who were initially asymptomatic but received diagnoses of TB within 3 months were assumed to have had progressive subclinical TB at enrollment; sputum culture of a representative subset of patients at enrollment [76] (Additional file 1: Table S6) supported this baseline prevalence estimate in a population among whom spontaneous resolution of subclinical TB is uncommon [77]. The prevalence of progressive subclinical disease was estimated within strata of baseline CD4 count $\left(<100,100-200,201-350\right.$, and $>350$ cells $\left./ \mathrm{mm}^{3}\right)$, and the lifetime cumulative incidence of progression from latent infection to active TB disease, for infections present at enrollment, was extrapolated from the TB incidence observed in months 4 to 12 (Additional file 1: Supplemental Methods 2a).

The HHC cohort is based on a large TPT scale-up effort in Pakistan. All household contacts of drug-susceptible TB patients underwent a symptom screen, chest radiography, detailed clinical evaluation, and (if able to expectorate) sputum Xpert ${ }^{\circ}$ MTB/RIF. Those with a negative symptom screen but a TB diagnosis were classified as having subclinical $\mathrm{TB}$, and we estimated the proportion of these subclinical cases who would progress to active disease if untreated. We used pooled data from published household contact cohorts $[39,40]$ to estimate the future incidence of progression from latent to active disease, relative to the prevalence of TB disease at the time of contact investigation, stratified by age $<5,5-15$, or $>15$ years (Additional file 1: Supplemental methods 2b).

The estimated prevalence of the subclinical progressor state was $3.5 \%(2.9-4.2 \%)$ among the newly diagnosed PWH and $0.4 \%(0.2-0.7 \%$, based on $0.8 \%$ [0.7-1.0\%] subclinical TB prevalence and 50\% [30-70\%] probability of progression) among the HHCs (Table 2). We estimated that there were between 0.2 and 1.2 subclinical progressors per latent progressor, depending on the cohort and the age or CD4 stratum (Table 2).

\section{TPT outcome parameters}

In clinical trials of TPT $[7,8,13,59]$, and in programmatic settings with well-documented outcomes [78], radiographic or bacteriologic screening has typically been used to exclude individuals with subclinical TB before initiating TPT. Therefore, we used such studies (after excluding estimates of the incidence attributable to nonadherence, reinfection, or preexisting drug resistance) to estimate the efficacy of TPT, and the risks of acquiring resistance when it was ineffective, among latent progressors (Additional file 1: Supplemental methods $2 \mathrm{~b}$ ). We assumed that $4 \mathrm{R}$ was at least as effective as 6 months of isoniazid and no more effective than 9 months of isoniazid [8]. The risk of acquiring resistance to the TPT drug was assumed to be lower for $4 R$ than for $6 \mathrm{H}$ and independent of susceptibilities to nonprescribed drug classes (Additional file 1: Supplemental methods $2 \mathrm{~d}$ ).

We assumed that TPT could also prevent progression from subclinical to active TB, but that it had lower efficacy against subclinical disease than against latent infection (failing to prevent 9\% [95\%CI 3-18\%] of progressions from the subclinical stage that could have been prevented at the latent stage; Table 1). In addition, those who progressed from subclinical to active disease despite TPT were at elevated risk (compared to latent progressors) of acquiring new drug resistance to the TPT drug in the process. For these subclinical progressors who received TPT, efficacy and resistance acquisition were estimated from historical clinical trials in which isoniazid or rifampicin was the only effective drug in a treatment regimen (Additional file 1: Supplemental Methods 2c and 2e).

\section{Simulation of outcomes}

For each cohort, we simulated TPT in combination with screening for subclinical TB and, alternatively, with only 
Table 1 Summary of model inputs (see Additional file 1 for details and numerical estimates)

\begin{tabular}{lll}
\hline Parameter type $\quad$ Definition & Data sources and approach to estimation $\begin{array}{l}\text { Table in Additional } \\
\text { file } 1 \text { with estimates, } \\
\text { uncertainty, and } \\
\text { references }\end{array}$ \\
\end{tabular}

\begin{tabular}{ll}
\hline Prevalence of "latent & Latent infections that will progress to active \\
progressor" state among & (symptomatic) TB disease at some time in the \\
each cohort considered & future \\
for TPT &
\end{tabular}
for TPT

Prevalence of "subclinical progressor" state among each cohort considered for TPT

TB disease that is undetectable by a symptom screen but is microbiologically active and will eventually progress to active disease if untreated

Efficacy of TPT for latent progressors, by regimen

Reduction in TPT efficacy when used during subclinical TB

Risk of acquiring resistance to the TPT drug, if latent TB progresses despite TPT

Risk of acquiring resistance to the TPT drug, if subclinical TB progresses despite TPT

Outcomes after active TB treatment
Proportion of latent progressions prevented, if initially susceptible to the TPT regimen and completes enough TPT to be at risk for acquired resistance

Proportion of TPT-preventable latent progressions that cannot be cured by TPT at the subclinical progressor stage

Applies to those whose TPT is unsuccessful and whose initial infections were not drugresistant.

As above

Risk of failure/relapse, with or without acquired isoniazid or rifampicin resistance, as a function of initial susceptibilities.

Lifetime cumulative incidence extrapolated from observed 12-month incidence ( $\mathrm{PWH}$ cohort) or baseline prevalence (household contacts) using published cohort studies and meta-analyses

Primary clinical data (Table 2):

Table S1

Symptom-negative individuals who progressed to active TB within 3 months (PWH) or who were diagnosed with TB during extensive baseline evaluation (household contacts, with adjustment for expected spontaneous resolution).

Network meta-analysis of clinical trial data, adjusted for reinfection, nonadherence, and baseline drug resistance.

$6 \mathrm{H}$ efficacy parametrized relative to $4 \mathrm{R}$ and assumed equal or less than 4R.

Bounded by the efficacy of TPT for latent TB and by the efficacy of monotherapy for symptomatic active TB.

Incidence of drug-resistant TB after TPT in clinical trials, adjusted for expected incidence from pre-existing drug resistance. Risk for isoniazid sets an upper bound on risk for rifampicin.

Treatment trials with a single effective drug. Large uncertainty is reflected in wide parameter distributions.

Table S1

\section{S1}




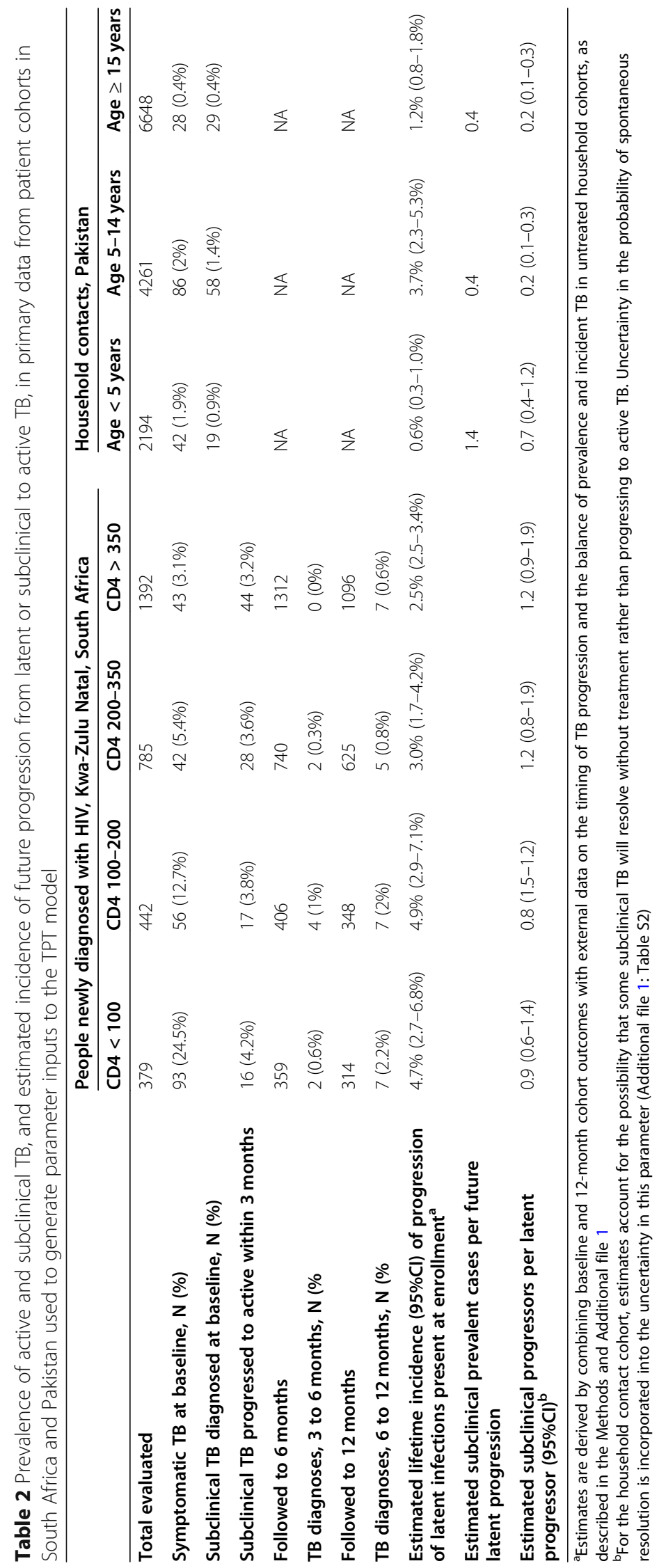


probabilistically sampled models, the 500 models with the highest values of that parameter to the 500 models with the lowest value of that parameter (while other parameters varied probabilistically as before). We also explored tradeoffs between screening and access, across a range of values for the impact of a screening requirement on TPT access.

\section{Results}

\section{Outcomes without TPT intervention}

Figure 2 shows the simulated incidence of active TB in each cohort, in the absence of TPT. Among 1000 PWH, our simulation predicted 71 (95\%UR 44-111) cases of active TB, of which $43 \%$ (34-53\%) arose from the progression of latent infection, $48 \%$ (38-56\%) began as subclinical TB disease at the start of the model, and 9\% (5$14 \%)$ were recurrences after unsuccessful treatment of one of these active TB cases arising from the latent or subclinical progressor states. The HHC cohort had a lower active TB incidence of 25 (16-37-) per 1000, and a lower proportion of those cases (15\% [95\%UR 9-34\%]) arose from TB disease that was subclinical at the start of the model (Fig. 2).

Focusing on drug resistance, we projected 3.3 (1.88.1) future RR/MDR cases and 4.1 (2.0-7.9) isoniazid monoresistant cases among $1000 \mathrm{PWH}$ and 0.9 (95\%UR 0.5-1.5) future RR/MDR cases and 2.2 (1.2-3.7) isoniazid monoresistant cases among 1000 HHCs. Nearly 50\% of these projected RR/MDR-TB cases and nearly $25 \%$ of projected isoniazid monoresistant cases were recurrences after a future course of active TB treatment, either because resistance was acquired during treatment, or because pre-existing resistance made treatment noncurative (Fig. 2).

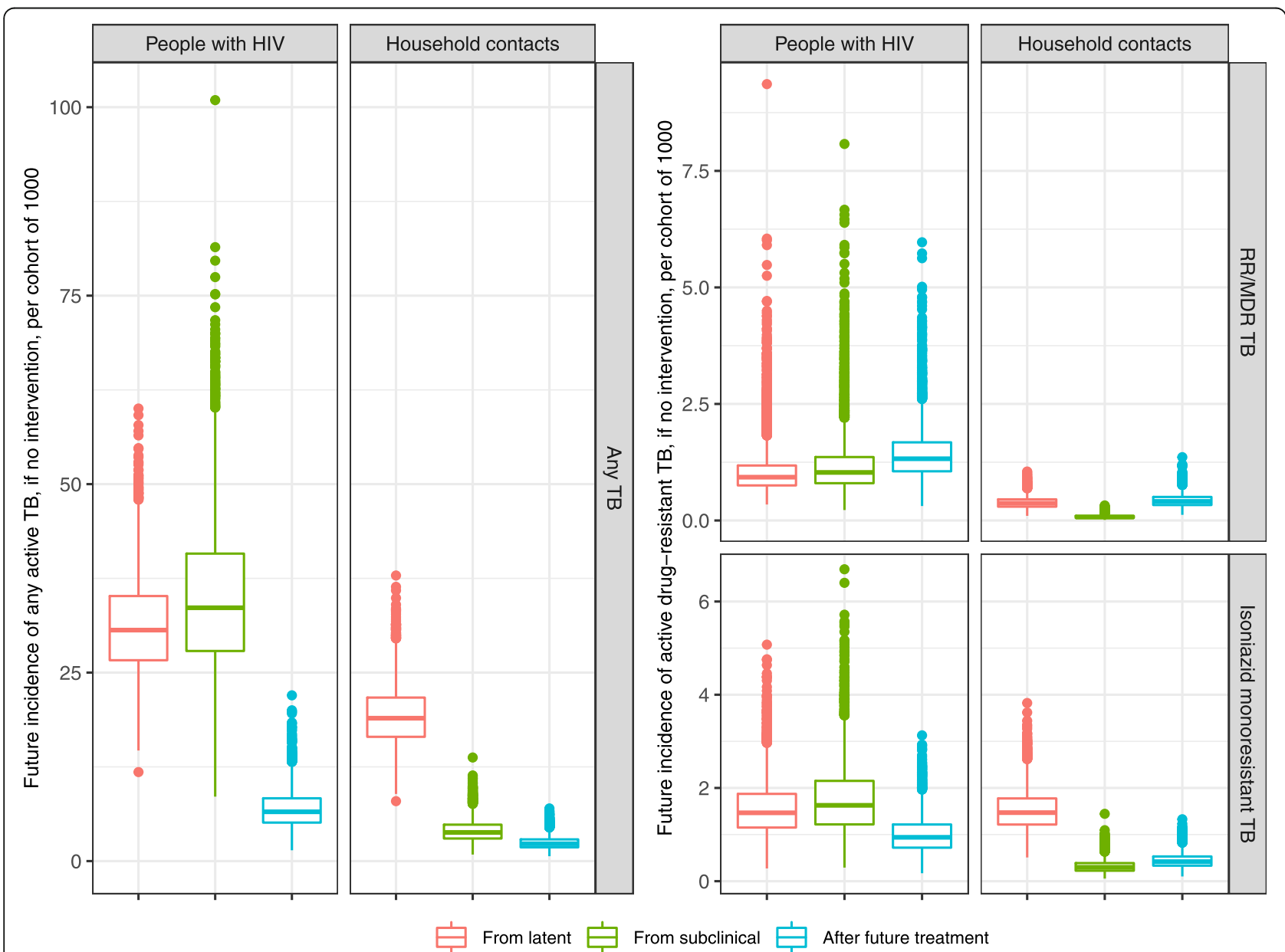

Fig. 2 Projected TB cases, in the absence of preventive therapy, among 1000 people newly diagnosed with HIV and 1000 TB household contacts. Simulated outcomes include the incidence of active TB (those cases arising from infections present before the start of the model) and the incidence of isoniazid- and/or rifampicin-resistant TB. Cases are classified based on whether they progressed from TB that was latent or subclinical at the time of TPT consideration (the start of the model) or were a recurrence of TB after non-curative treatment. Boxes show the median and interquartile range of projections when parameters are sampled probabilistically, and dots show outlier simulations that differ from the median by more than $1.5 x$ the interquartile range in either direction 


\section{Impact of TPT with symptom-only TB screening}

When only symptom-based screening for TB disease was performed (i.e., when those with subclinical TB received TPT along with the latently infected), and $4 \mathrm{R}$ was used as the TPT regimen, 45 (95\%UR 24-79) active TB cases were averted among $1000 \mathrm{PWH}$; these represented 64\% (95\%UR 40-89\%) of all incident active TB cases not attributable to future TB exposure (Fig. 3). Similarly, among $1000 \mathrm{HHCs}$, symptom screening and 4R prevented 17 (95\%UR 9-29) active TB cases or $68 \%$ (95\%UR 43-94\%) of the incident cases arising from infections present at the time of the intervention (Additional file 1: Figure S1). Due to the lower assumed efficacy of $6 \mathrm{H}$ and a higher prevalence of preexisting resistance to isoniazid versus rifampicin, using $6 \mathrm{H}$ as the TPT regimen after symptom screening averted $37 \mathrm{~TB}$ cases $(19-66,52-73 \%)$ among PWH and $13 \mathrm{~TB}$ cases
(7-23, 34-75\%) among HHCs (Fig. 3 and Additional file 1: Figure S1).

Meanwhile, 4R also averted 3.0 (95\% UR1.3-6.1) isoniazid-monoresistant cases among $\mathrm{PWH}$, while adding $3.5(0.2-11.0)$ rifampicin-resistant cases; most (82\%, 95\%UR 72-97\%) of the net increase in rifampicin resistance was rifampicin-monoresistant as opposed to multidrug-resistant TB. In the HHC cohort, where overall TB incidence was lower, these projections decreased to $1.6(0.8-2.9)$ isoniazid monoresistant cases averted and $0.4(0-1.5)$ RR/MDR cases (86\% [73-99\%] rifampicin monoresistant) added per 1000 individuals. Using $6 \mathrm{H}$ as the TPT regimen, by contrast, increased net isoniazid resistance (adding 6.2 [1.8-16] isoniazid-resistant cases among PWH and 0.8 [0.2-2.3] among HHCs), while having minimal impact on net RR/MDR TB (median 0.1 case averted [95\%UR 2.8 averted to 0.7 added]

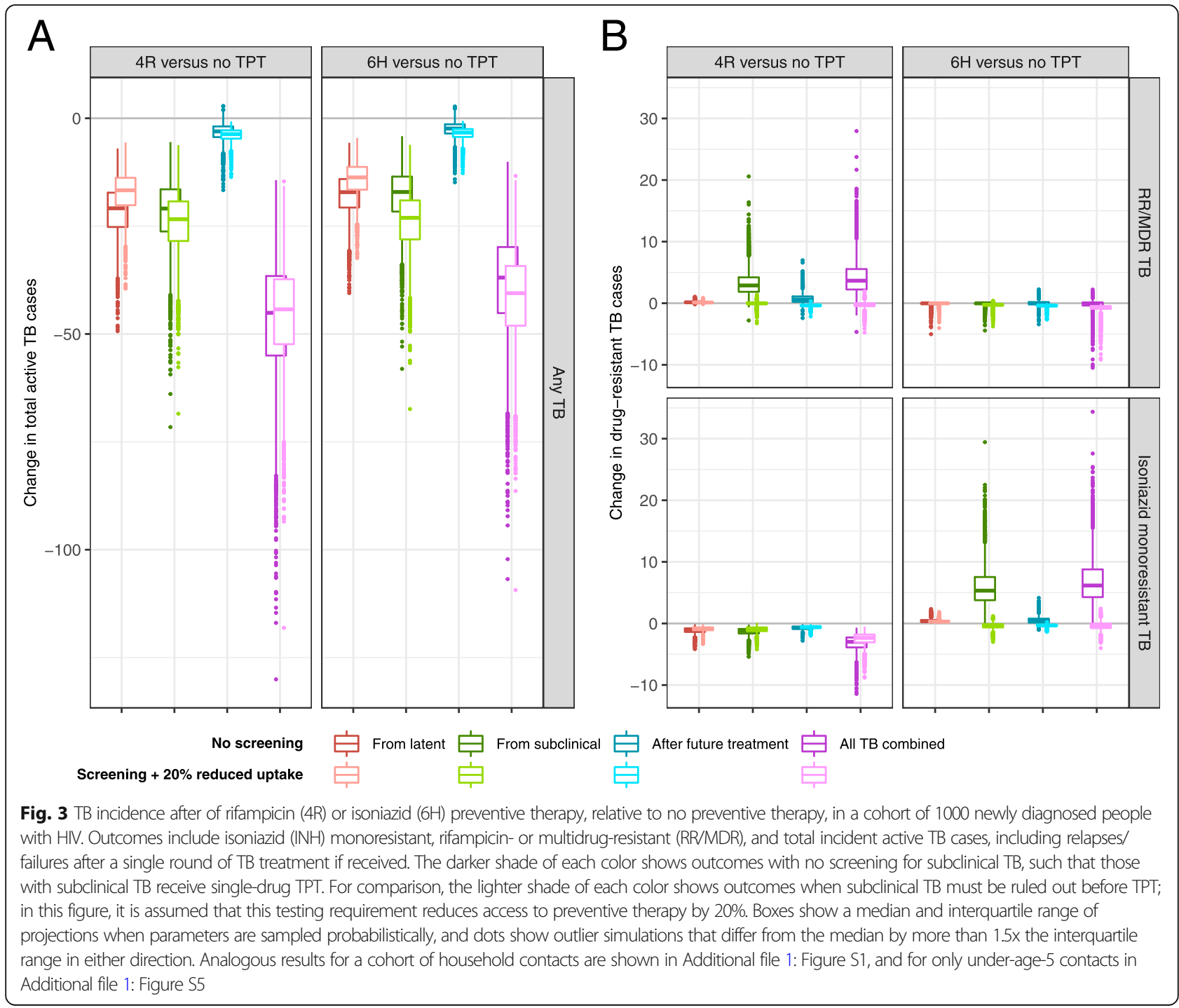


Table 3 Median outcomes of TPT with 4R in cohorts of 1000 PWH or 1000 TB household contacts, compared to no TPT or to 6H, under different scenarios of subclinical TB screening and associated intervention access

\begin{tabular}{|c|c|c|c|c|c|c|}
\hline & $\begin{array}{l}4 \mathrm{R}, \\
\text { symptom } \\
\text { screening } \\
\text { only }\end{array}$ & $\begin{array}{l}\text { 4R, Subclinical TB } \\
\text { screening, same } \\
\text { access }\end{array}$ & $\begin{array}{l}\text { 4R, Subclinical TB } \\
\text { screening, } 20 \% \\
\text { reduced access }\end{array}$ & $\begin{array}{l}6 \mathrm{H}, \\
\text { symptom } \\
\text { screening } \\
\text { only }\end{array}$ & $\begin{array}{l}6 \mathrm{H}, \text { Subclinical TB } \\
\text { screening, same } \\
\text { access }\end{array}$ & $\begin{array}{l}6 \mathrm{H}, \text { Subclinical TB } \\
\text { screening, } 20 \% \\
\text { reduced access }\end{array}$ \\
\hline \multicolumn{7}{|l|}{ PWH cohort } \\
\hline $\begin{array}{l}\text { Expected cases of active } \\
\text { TB without TPT }\end{array}$ & 71 & 71 & 71 & 71 & 71 & 71 \\
\hline $\begin{array}{l}\text { Expected cases of active } \\
\text { TB with TPT \# }\end{array}$ & 25 & 16 & 27 & 33 & 20 & 31 \\
\hline $\begin{array}{l}\text { Net change in total } \\
\text { active TB cases (versus } \\
\text { no TPT) }\end{array}$ & -45 & -55 & -44 & -37 & -51 & -41 \\
\hline $\begin{array}{l}\text { Net change in INH } \\
\text { monoresistant cases } \\
\text { (versus no TPT) }\end{array}$ & -3 & -2.9 & -2.3 & 6.2 & -0.48 & -0.38 \\
\hline $\begin{array}{l}\text { Net change in RIF } \\
\text { monoresistant cases } \\
\text { (versus no TPT) }\end{array}$ & 3 & 0.3 & 0.24 & -0.23 & -0.11 & -0.09 \\
\hline $\begin{array}{l}\text { Net change in MDR } \\
\text { cases (versus no TPT) }\end{array}$ & 0.63 & -0.56 & -0.45 & 0.18 & -0.59 & -0.47 \\
\hline $\begin{array}{l}\text { Net change in total DR } \\
\text { cases (versus no TPT) }\end{array}$ & -0.85 & -1.5 & -1.2 & 1.1 & -0.69 & -0.55 \\
\hline $\begin{array}{l}\text { Symptomatic TB cases } \\
\text { averted per RR/MDR } \\
\text { added (vs no TPT) }\end{array}$ & 12 & b & b & b & $\mathrm{b}$ & b \\
\hline $\begin{array}{l}\text { INH monoresistance } \\
\text { averted per RR/MDR } \\
\text { added (vs no TPT) }\end{array}$ & 0.78 & b & b & b & $\mathrm{b}$ & b \\
\hline $\begin{array}{l}\text { Symptomatic TB cases } \\
\text { averted per RR/MDR } \\
\text { added (vs } 6 \mathrm{H} \text { ) }\end{array}$ & 2 & 7.2 & 7.2 & NA & NA & NA \\
\hline $\begin{array}{l}\text { INH monoresistance } \\
\text { averted per RR/MDR } \\
\text { added (vs } 6 \mathrm{H} \text { ) }\end{array}$ & 2.3 & 4 & 4 & NA & NA & NA \\
\hline \multicolumn{7}{|l|}{ Household contact cohort } \\
\hline $\begin{array}{l}\text { Expected cases of active } \\
\text { TB without TPT }\end{array}$ & 25 & 25 & 25 & 25 & 25 & 25 \\
\hline $\begin{array}{l}\text { Expected cases of active } \\
\text { TB with TPT \# }\end{array}$ & 7.8 & 6.8 & 10 & 12 & 10 & 13 \\
\hline $\begin{array}{l}\text { Net change in total } \\
\text { active TB cases (versus } \\
\text { no TPT) }^{\text {a }}\end{array}$ & -17 & -18 & -15 & -13 & -15 & -12 \\
\hline $\begin{array}{l}\text { Net change in INH } \\
\text { monoresistant cases } \\
\text { (versus no TPT) }\end{array}$ & -1.6 & -1.6 & -1.3 & 0.84 & -0.02 & -0.02 \\
\hline $\begin{array}{l}\text { Net change in RIF } \\
\text { monoresistant cases } \\
\text { (versus no TPT) }\end{array}$ & 0.39 & 0.09 & 0.07 & -0.06 & -0.05 & -0.04 \\
\hline $\begin{array}{l}\text { Net change in MDR } \\
\text { cases (versus no TPT) }\end{array}$ & 0.02 & -0.1 & -0.08 & 0 & -0.06 & -0.05 \\
\hline $\begin{array}{l}\text { Net change in total DR } \\
\text { cases (versus no TPT) }\end{array}$ & -0.56 & -0.56 & -0.44 & 0.11 & -0.09 & -0.07 \\
\hline $\begin{array}{l}\text { Symptomatic TB cases } \\
\text { averted per RR/MDR } \\
\text { added (vs no TPT) }\end{array}$ & 37 & b & b & b & $\mathrm{b}$ & b \\
\hline INH monoresistance & 3.5 & b & b & b & b & b \\
\hline
\end{tabular}


Table 3 Median outcomes of TPT with 4R in cohorts of 1000 PWH or 1000 TB household contacts, compared to no TPT or to 6H, under different scenarios of subclinical TB screening and associated intervention access (Continued)

\begin{tabular}{|c|c|c|c|c|c|c|}
\hline & $\begin{array}{l}4 \mathrm{R}, \\
\text { symptom } \\
\text { screening } \\
\text { only }\end{array}$ & $\begin{array}{l}\text { 4R, Subclinical TB } \\
\text { screening, same } \\
\text { access }\end{array}$ & $\begin{array}{l}\text { 4R, Subclinical TB } \\
\text { screening, } 20 \% \\
\text { reduced access }\end{array}$ & $\begin{array}{l}6 \mathrm{H}, \\
\text { symptom } \\
\text { screening } \\
\text { only }\end{array}$ & $\begin{array}{l}\text { 6H, Subclinical TB } \\
\text { screening, same } \\
\text { access }\end{array}$ & $\begin{array}{l}6 \mathrm{H}, \text { Subclinical TB } \\
\text { screening, } 20 \% \\
\text { reduced access }\end{array}$ \\
\hline \multicolumn{7}{|l|}{$\begin{array}{l}\text { averted per RR/MDR } \\
\text { added (vs no TPT) }\end{array}$} \\
\hline $\begin{array}{l}\text { Symptomatic TB cases } \\
\text { averted per RR/MDR } \\
\text { added (vs } 6 \mathrm{H})\end{array}$ & 7.2 & 24 & 24 & NA & NA & NA \\
\hline $\begin{array}{l}\text { INH monoresistance } \\
\text { averted per RR/MDR } \\
\text { added (vs } 6 \mathrm{H} \text { ) }\end{array}$ & 5 & 13 & 13 & NA & NA & NA \\
\hline
\end{tabular}

and median 0.1 case averted [95\%UR 0.2 averted to 0.1 added], respectively).

Thus, compared to no TPT, each TPT regimen was expected to prevent more than 10 cases of active TB for each added case of resistance to that TPT drug. Specifically, 4R prevented median 12 (95\%UR 3-102) active TB cases among PWH and 37 (95\%UR 9-580) among HHCs for each rifampicin-resistant (monoresistant or MDR) case added (Table 3). Similarly, $6 \mathrm{H}$ prevented 6 [IQR 2-26] active TB cases among PWH and 15 (95\%UR 5-98) among HHCs for each isoniazid-resistant (monoresistant or MDR) case added. If we compared 4R and $6 \mathrm{H}$ head-to-head with only symptom-based screening, the choice to use $4 \mathrm{R}$ rather than $6 \mathrm{H}$ led to reductions in incident active TB (uncertain in magnitude, and largely attributable to our assumption that $4 R$ is somewhat more efficacious), and it traded modest a net increase in isoniazid resistance for a smaller net increase in rifampicin resistance: among $\mathrm{PWH}$, the decision to use $4 \mathrm{R}$ instead of $6 \mathrm{H}$ added one case of rifampicin resistance for every $2(0.4-14)$ incremental cases of active TB and every 2 (1-8) cases of isoniazid monoresistance averted, compared to $6 \mathrm{H}$. Among the $\mathrm{HHC}$ cohort (which had fewer subclinical progressors and a higher prevalence of isoniazid monoresistance), the analogous estimates were one case of rifampicin resistance added for every 7 (2-80) active TB cases averted and every 5 (2-40) isoniazid-resistant cases averted.

\section{Impact of TPT after subclinical TB screening}

The lighter-colored boxes in Fig. 3 and Additional file 1: Figures S1 and S2 show the impact of $4 \mathrm{R}$ or $6 \mathrm{H}$ when cohorts were screened for subclinical TB prior to initiating TPT, under the arbitrary assumption that the screening requirement reduced access to TPT by $20 \%$. The ability of TPT to prevent progression of latent TB was reduced in proportion to this reduction in access (Fig.
3A and Additional file 1: Figure S1 Panel A, red boxes), but that the effect was offset by the benefits of appropriately treating subclinical TB that would have progressed to active disease had it been treated with only TPT (green boxes), resulting in similar overall active TB incidence (pink boxes; with 4R preventing 62\% [51-73\%] of incident active TB among PWH and 58\% [41-76\%] among $\mathrm{HHCs}$, for example).

If the screening requirement reduced TPT access by a larger amount, then its effect on overall TB incidence was detrimental; for example, among $1000 \mathrm{PWH}$, if screening for subclinical TB reduced intervention access by $50 \%$, then it lowered the impact of $4 \mathrm{R}$ to $28(17-45)$ cases of active TB averted, compared to 45 (24-80) averted by $4 \mathrm{R}$ when paired with symptom-only screening. The predicted reduction in access at which a screening requirement had no net effect on the overall incidence of active TB ranged from 10 to 30\% depending on the cohort and regimen, with the lower thresholds estimated for the more efficacious regimen (4R) (Fig. 4 and Additional file 1: Figure S3).

Although screening for subclinical TB could reduce the overall TB prevention impact of TPT if it significantly restricted access, it had the benefit of eliminating net acquisition of drug resistance, because the prevention of TB cases that would have acquired resistance during future treatment outweighed the number of individuals who acquired resistance during TPT in most simulations (Fig. 3B, light-colored boxes).

\section{Sensitivity analysis}

In one-way sensitivity analysis, the largest contributors to uncertainty about the absolute number of $\mathrm{TB}$ or drug-resistant cases prevented by TPT were the estimated efficacy of the TPT regimens and the proportion of the cohort expected to progress from latent or subclinical to active TB. Because we did not differentiate 


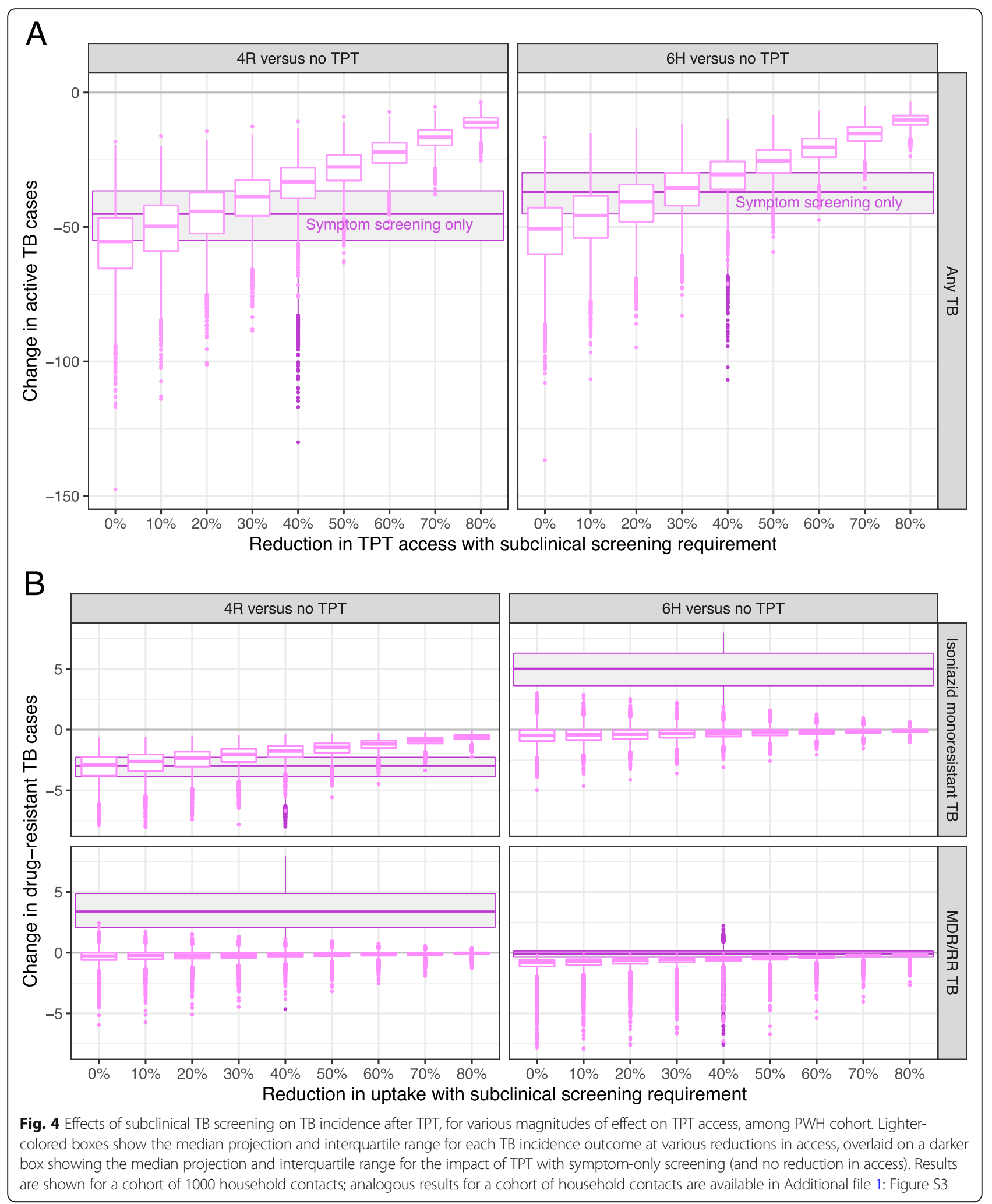

TPT efficacy between PWH and HHCs, the different prevalence of the subclinical progressor state and different future cumulative incidence of latent TB progression were the main sources of difference between the PHW and HHC cohorts. Drug-resistance-related outcomes were also sensitive to the estimated risk of resistance 
acquisition when subclinical TB was not cured by TPT (Additional file 1: Figure S3).

\section{Discussion}

In this TB preventive therapy modeling study, a $4 \mathrm{R} T P T$ regimen-when paired with sensitive screening for subclinical TB and available to at least $80 \%$ of the eligible population-was expected to prevent $>60 \%$ (and highly likely to prevent $>40 \%$ ) of progression to active TB among both PWH and household contacts of TB patients, while also reducing isoniazid-resistant $\mathrm{TB}$ and having no clinically meaningful net effect on rifampicinresistant TB. Thus, in settings where testing for subclinical TB is available with only a small reduction in TPT access, such testing has the advantage of allowing patients to benefit from the short duration, efficacy, and tolerability [8] of the $4 \mathrm{R}$ regimen without risk of adding to the burden of rifampicin resistance. X-ray or other tests for subclinical TB may not be readily available in high-TB-burden settings, however. Despite improving radiographic technology and illustrative successes in implementing it for TB screening in some low-resource settings [79-81], requirements to perform sensitive screening may limit access to TPT in many parts of the world. In clinical situations where screening for subclinical TB can be offered, it has both TB prevention and drug resistance prevention advantages, and our results can aid in economic evaluations of the cost-effectiveness of such screening. If, however, subclinical TB screening will substantially reduce TPT access in certain patient populations or care settings, then guidelines that support initiation of TPT after a negative symptom screen are likely to maximize TB prevention. For the $4 \mathrm{R}$ regimen, we estimated a $10-20 \%$ reduction in access as the threshold above which a symptom-only screening policy would prevent more active TB (while also minimizing drug resistance) than implementing TPT with a subclinical TB screening requirement. The precise threshold at which preventive efficacy offsets reductions in access is uncertain; however, our results suggest that it may range from 0 to $60 \%$ depending on the prevalence and outcomes of subclinical TB in the TPT eligible population.

When considering allowing symptom-only screening to maximize TPT access, decision-makers must weigh maximal prevention of TB (achievable with the 4R regimen and broad eligibility criteria) against the potential selection of rifampicin and/or isoniazid resistance. Our analysis indicates that without subclinical TB screening, $4 \mathrm{R}$ would avert multiple cases of active $\mathrm{TB}$ for every case of rifampicin resistance added (point estimates 12 among PWH and 37 among HHCs, though with wide uncertainty); this corresponded to an absolute risk of one case of rifampicin resistance for every 300 (among PWH) to 2400 (among HHCs) recipients of the 4R TPT regimen. This risk may be judged to be acceptable; if rifampicin-susceptibility testing (e.g., Xpert MTB/RIF) and alternative regimens for rifampicin-monoresistant $\mathrm{TB}$ are available to people with a known rifampicin TPT history, then the rifampicin resistance that develops from inadvertent $4 \mathrm{R}$ monotherapy may be readily detected and appropriately treated. Alternatively, if subclinical TB screening is not feasible, but a small increase in the risk of rifampicin resistance is considered unacceptable because of rifampicin's crucial role in active TB treatment regimens, then decision-makers may forego the efficacy, safety, and operational advantages of the $4 \mathrm{R}$ regimen in lieu of the $6 \mathrm{H}$ regimen (which we estimated would add more isoniazid-resistant cases than the rifampicin resistance added by $4 \mathrm{R}$, and would prevent slightly less TB overall, but would avoid rifampicin resistance).

Among models of TPT and drug resistance, our analysis is the first to our knowledge to model rifamycinbased regimens and one of few that explicitly simulate the prevalence and outcomes of subclinical TB. However, our work builds on previous models of the interplay of TPT's clinical benefits and potential drugresistance risks $[50,82]$. Our results are consistent with a model of multidrug-resistant TB preventive therapy and acquired fluoroquinolone resistance [83], in the conclusion that among people with latent $\mathrm{TB}$, resistance generated by TPT is likely to be offset by a reduction in future opportunities for resistance to be acquired during TB treatment.

Because clinical trials of TPT identify and exclude those with subclinical TB, there is considerable uncertainty about the outcomes of TPT in this population. Many have paucibacillary disease that may be curable with a single TPT drug; however, even high bacillary burden (e.g., smear-positive) prevalent TB is often asymptomatic [51]. Although our model provides a high level of certainty for some findings-for instance, that $4 \mathrm{R}$ paired with subclinical TB screening will not lead to large increases in the prevalence of rifampicin resistance-other results are subject to uncertainties about the course of subclinical TB. For example, the number of active TB cases preventable by each TPT regimen depends not only on the efficacy of each TPT regimen against latent $\mathrm{TB}$, but also on how often subclinical TB progresses to symptomatic disease and how often TPT, if given at the subclinical stage, is able to halt that progression. To allow more precise estimates, data are needed on outcomes after TPT in patient populations from which subclinical TB has not been systematically excluded. In the ongoing global scale-up of TPT without a strict requirement for chest radiography, programmatic data on the subsequent incidence of TB and burden of drug resistance should be monitored to better understand these outcomes. 
Our uncertainty ranges reflect uncertainty in the outcomes of monotherapy for progressive subclinical TB, including the probabilities of cure and the risks of resistance acquisition. Available data reflect outcomes of single-drug therapy for truly latent infection and for symptomatic active disease, but the spectrum of bacillary burden in subclinical disease and the associated treatment outcomes are less well characterized. We also modeled only single-drug TPT regimens. Our results may be interpreted as an upper bound for the resistance risks associated with 2-drug regimens such as $3 \mathrm{HP}$ and $3 \mathrm{HR}$, but further work is needed to understand the extent to which outcomes differ for a two-drug TPT regimen, particularly when dosed at a long interval relative to isoniazid's half-life. We simplified drug resistance as dichotomous and assumed that a given TPT regimen was equally efficacious in patients with and without HIV. HIV may theoretically reduce the ability of singledrug therapy to cure subclinical disease, but data from active TB treatment among PWH on antiretroviral therapy [84] and from clinical trials of 4R TPT [85] suggest that differences are minimal. Because we did not use a transmission model, our analysis does not consider how the evolution of TB epidemics affects TPT-associated drug resistance. Finally, we focused only on TB outcomes within the modeled cohort and did not consider other outcomes that may differ in important ways between TPT strategies. For example, screening for subclinical TB will incur the costs of radiographic screening and confirmatory testing, with cost-effectiveness implications. It may also lead to adverse events from treating patients for subclinical TB, including some who would never have developed symptoms; these adverse effects could be limited by a test that was specific for those subclinical cases that are progressive, but no such test currently exists. On the other hand, we did not account for the potential that identifying and treating patients with subclinical TB may, in some cases, prevent asymptomatic transmission, including transmission from those whose disease might eventually resolve without intervention.

\section{Conclusions}

In summary, because subclinical TB is often present in populations considered for TPT, chest radiography is advisable both to increase TB detection and to minimize the risk that TPT could generate drug resistance in people with active TB. Such testing is likely to reduce TB incidence even if the requirement for testing reduces TPT access by as much as $20 \%$. With testing for subclinical TB in place, $4 \mathrm{R}$ is predicted to have better TB outcomes than $6 \mathrm{H}$ without posing resistance-related risks. When such screening is infeasible and active TB must be excluded based on symptoms alone, regimen selection will need to account for the importance of incident $\mathrm{TB}$ and isoniazid resistance relative to rifampicin resistance, while also considering the tolerability and cost-effectiveness advantages of $4 R$.

\section{Abbreviations \\ TB: Tuberculosis; TPT: Tuberculosis preventive therapy; $6 \mathrm{H}$ : Isoniazid for 6 months; 4R: Rifampicin for 4 months; 3HP: Weekly rifapentine and isoniazid for 3 months; PWH: People living with HIV; HHCs: Household contacts; 95\%UR: 95\% uncertainty range}

\section{Supplementary information}

The online version contains supplementary material available at https://doi. org/10.1186/s12916-021-02189-w.

\section{Additional file 1: Supplemental methods, Tables S1-S6, and Fig-}

ures S1-S5. Supplemental methods - Additional details of primary human subjects data collection, estimation of model parameters, statetransition model, and approach to probabilistic parameter sampling.

Table S1. Parameter estimates, sizes of latent and subclinical progressor populations. Table S2. Parameter estimates, preventive therapy efficacy and related parameters. Table S3. Parameter estimates, preventive therapy resistance acquisition. Table S4. Parameter estimates, TB treatment outcomes. Table S5. Composition of cohorts with respect to initial drug resistance and age or CD4 count. Table S6. Correspondence between baseline culture-positive TB prevalence and 3-month clinical TB incidence in cohort of people with newly diagnosed HIV and a negative TB symptom screen in Kwa-Zulu Natal. Fig S1. - Projected outcomes of $4 \mathrm{R}$ or $6 \mathrm{H}$, each compared to no TPT, among a cohort of 1000 all-age Household contacts. Fig S2. Head-to-head comparison of TB outcomes after TPT, comparing $4 \mathrm{R}$ regimen to $6 \mathrm{H}$. Fig $\mathbf{S 3}$. Effect of reduced access on the impact of subclinical TB screening prior to TPT, among HHC cohort. Fig S4. Sensitivity of key results to individual parameters. Fig S5 - Projected outcomes of $4 \mathrm{R}$ or $6 \mathrm{H}$, each compared to no TPT, among 1000 household contacts, when TPT is only considered for the $17 \%$ of contacts who are under age 5

\section{Acknowledgements}

Not applicable

\section{Authors' contributions}

EAK, HH, AK, AT, RM, and PKD conceived the study. PKD and HH provided primary data. EAK, RK, and $\mathrm{HH}$ analyzed data. EAK developed the model, generated results and figures, and drafted the manuscript. All authors contributed to the interpretation of results and critical revision of the manuscript, and the authors approved the final version of the manuscript.

\begin{abstract}
Funding
This work was supported by the US National Institutes of Health (K08Al127908 to EAK, and Al108293, Al143351, Al136648 to PKD), the Brazilian National Council of Scientific and Technological Development (CNPq 303267/2018-6) to AT, and The Global Fund PAK-T-TIH-1628. The study sponsors had no role in study design; in the collection, analysis, and interpretation of data; in the writing of the report; or in the decision to submit the paper for publication.
\end{abstract}

\section{Availability of data and materials}

Code and summary data used for this analysis are available at https://github. com/eakendall/RifTPT.

\section{Declarations}

Ethics approval and consent to participate

This project did not enroll participants or use identifiable human subject data. For the underlying studies that provided deidentified summary data, approval is described in Additional file 1. 


\section{Consent for publication}

Not applicable.

\section{Competing interests}

The authors declare that they have no competing interests.

\section{Author details}

'Division of Infectious Diseases and Center for Tuberculosis Research, Johns Hopkins University School of Medicine, 1550 Orleans Street, Baltimore, Maryland 21287, USA. ${ }^{2}$ Interactive Research and Development (IRD) Global, 583 Orchard Road \#06-01 Forum, Singapore, Singapore. ${ }^{3}$ Emerging Diseases Epidemiology Unit, Institut Pasteur, 25-28 Rue du Dr Roux, 75015 Paris, France. ${ }^{4}$ Department of Epidemiology, University of Washington, 3980 15th Ave NE, Seattle, Washington 98195, USA. ${ }^{5}$ Instituto de Medicina Social, Universidade do Estado do Rio de Janeiro, R. São Francisco Xavier, Rio de Janeiro 20550-900, Brazil. ${ }^{6}$ Respiratory Epidemiology and Clinical Research Unit, Montreal Chest Institute \& McGill International TB Centre, 3650 St-Urbain Street, Montreal, Quebec H2X 2P, Canada. ${ }^{7}$ Departments of Global Health, Medicine, and Epidemiology, University of Washington, Box 359927, 325 Ninth Ave, Seattle, Washington 98104, USA.

\section{Received: 9 July 2021 Accepted: 15 November 2021}

Published online: 14 December 2021

\section{References}

1. Ferebee SH. Controlled chemoprophylaxis trials in tuberculosis. A general review. Bibl Tuberc. 1970;26:28-106.

2. Badje A, Moh R, Gabillard D, Guéhi C, Kabran M, Ntakpé J-B, et al. Effect of isoniazid preventive therapy on risk of death in west African, HIV-infected adults with high CD4 cell counts: long-term follow-up of the Temprano ANRS 12136 trial. Lancet Glob Health. 2017;5(11):e1080-9. https://doi.org/1 0.1016/S2214-109X(17)30372-8.

3. Rangaka MX, Cavalcante SC, Marais BJ, Thim S, Martinson NA, Swaminathan $\mathrm{S}$, et al. Controlling the seedbeds of tuberculosis: diagnosis and treatment of tuberculosis infection. Lancet. 2015;386(10010):2344-53. https://doi.org/1 0.1016/S0140-6736(15)00323-2.

4. Fox GJ, Dobler CC, Marais BJ, Denholm JT. Preventive therapy for latent tuberculosis infection - the promise and the challenges. Int J Infect Dis. 2017:56:68-76. https://doi.org/10.1016/j.jij.2016.11.006.

5. Dye C, Glaziou P, Floyd K, Raviglione M. Prospects for tuberculosis elimination. Annu Rev Public Health. 2013;34(1):271-86. https://doi.org/1 0.1146/annurev-publhealth-031912-114431.

6. World Health Organization. The END TB Strategy. Geneva: WHO; 2015.

7. Sterling TR, Scott NA, Miro JM, Calvet G, La Rosa A, Infante R, et al. Three months of weekly rifapentine plus isoniazid for treatment of M. tuberculosis infection in HIV co-infected persons. AIDS. 2016. https://doi.org/10.1097/QA D. 0000000000001098 .

8. Menzies D, Adjobimey M, Ruslami R, Trajman A, Sow O, Kim H, et al. Four months of rifampin or nine months of isoniazid for latent tuberculosis in adults. N Engl J Med. 2018;379(5):440-53. https://doi.org/10.1056/NEJMoa1 714283.

9. Swindells S, Ramchandani R, Gupta A, Benson CA, Leon-Cruz J, Mwelase N, et al. One month of rifapentine plus isoniazid to prevent HIV-related tuberculosis. N Engl J Med. 2019;380(11):1001-11. https://doi.org/10.1056/ NEJMoa1806808

10. Bastos ML, Campbell JR, Oxlade O, Adjobimey M, Trajman A, Ruslami R, et al. Health system costs of treating latent tuberculosis infection with four months of rifampin versus nine months of isoniazid in different settings. Ann Intern Med. 2020;173(3):169-78. https://doi.org/10.7326/M19-3741.

11. World Health Organization. Latent TB infection: updated and consolidated guidelines for programmatic management. Geneva: World Health Organization; 2019

12. Sterling TR. Guidelines for the treatment of latent tuberculosis infection: recommendations from the National Tuberculosis Controllers Association and CDC, 2020. MMWR Recomm Rep. 2020;69(1):1-11. https://doi.org/10.1 5585/mmwr.rr6901a1.

13. Balcells ME, Thomas SL, Godfrey-Faussett P, Grant AD. Isoniazid preventive therapy and risk for resistant tuberculosis. Emerg Infect Dis. 2006;12(5):74451. https://doi.org/10.3201/eid1205.050681.
14. World Health Organization Department of HIV/AIDS, Stop TB Department. Guidelines for intensified tuberculosis case-finding and isoniazid preventive therapy for people living with HIV in resource-constrained settings. Geneva: WHO; 2011.

15. Pathmanathan I, Ahmedov S, Pevzner E, Anyalechi G, Modi S, Kirking H, et al. TB preventive therapy for people living with HIV - key considerations for scale-up in resource-limited settings. Int J Tuberc Lung Dis. 2018;22(6): 596-605. https://doi.org/10.5588/ijtld.17.0758.

16. Davies $P$, Ormerod $P$. The role of four months of rifampicin in the treatment of latent tuberculosis infection. Am J Respir Crit Care Med. 2005;172(4):509. https://doi.org/10.1164/ajrccm.172.4.950.

17. Batt J, Khan K. Responsible use of rifampin for the treatment of latent tuberculosis infection. CMAJ. 2019;191(25):E678-9. https://doi.org/10.1503/ cmaj.190081.

18. Dhoot R, Humphrey JM, O'Meara P, Gardner A, McDonald CJ, Ogot K, et al. Implementing a mobile diagnostic unit to increase access to imaging and laboratory services in western Kenya. BMJ Glob Health. 2018;3(5):e000947. https://doi.org/10.1136/bmjgh-2018-000947.

19. Perry L, Malkin R. Effectiveness of medical equipment donations to improve health systems: how much medical equipment is broken in the developing world? Med Biol Eng Comput. 2011;49(7):719-22. https://doi.org/10.1007/s11 517-011-0786-3.

20. Ginderdeuren EV, Bassett J, Hanrahan C, Mutunga L, Rie AV. Health system barriers to implementation of TB preventive strategies in South African primary care facilities. PLoS One. 2019;14(2):e0212035. https://doi.org/10.13 71/journal.pone.0212035.

21. World Health Organization. Global tuberculosis report. Geneva. 2019:2019.

22. Zero TB Karachi (Pakistan). In: Zero TB initiative: strategies to eliminate tuberculosis one community at a time. Mohammed Bin Rashid University, Dubai: Harvard Medical School Center for Global Health Delivery-Dubai; 2018.

23. United Nations General Assembly. Political declaration of the high-level meeting of the General Assembly on the fight against tuberculosis. 2018.

24. Menzies D, Benedetti A, Paydar A, Royce S, Madhukar P, Burman W, et al. Standardized treatment of active tuberculosis in patients with previous treatment and/or with mono-resistance to isoniazid: a systematic review and meta-analysis. PLoS Med. 2009;6(9):e1000150. https://doi.org/10.1371/ journal.pmed. 1000150

25. Kunkel A, Crawford FW, Shepherd J, Cohen T. Benefits of continuous isoniazid preventive therapy may outweigh resistance risks in a declining tuberculosis/HIV coepidemic. AIDS. 2016;30(17):2715-23. https://doi.org/10.1 097/QAD.0000000000001235.

26. Lew W, Pai M, Oxlade O, Martin D, Menzies D. Initial drug resistance and tuberculosis treatment outcomes: systematic review and meta-analysis. Ann Intern Med. 2008;149(2):123-34. https://doi.org/10.7326/0003-4819-149-2-2 00807150-00008.

27. Dye C, Espinal MA. Will tuberculosis become resistant to all antibiotics? Proc Biol Sci. 2001;268(1462):45-52. https://doi.org/10.1098/rspb.2000.1328.

28. Murray J, Sonnenberg P, Shearer S, Godfrey-Faussett P. Drug-resistant pulmonary tuberculosis in a cohort of southern African goldminers with a high prevalence of HIV infection. S Afr Med J. 2000;90:381-6.

29. A concurrent comparison of isoniazid plus PAS with three regimens of isoniazid alone in the domiciliary treatment of pulmonary tuberculosis in South India. Bull World Health Organ. 1960;23:535-85.

30. Gegia M, Winters N, Benedetti A, van Soolingen D, Menzies D. Treatment of isoniazid-resistant tuberculosis with first-line drugs: a systematic review and meta-analysis. Lancet Infect Dis. 2017;17(2):223-34. https://doi.org/10.1016/ S1473-3099(16)30407-8.

31. Park S, Jo K-W, Lee SD, Kim WS, Shim TS. Treatment outcomes of rifampinsparing treatment in patients with pulmonary tuberculosis with rifampinmono-resistance or rifampin adverse events: a retrospective cohort analysis. Respir Med. 2017;131:43-8. https://doi.org/10.1016/j.rmed.2017.08.002.

32. World Health Organization. Global tuberculosis report 2020. Geneva: WHO; 2020.

33. Republic of South Africa Department of Health. The South African antiretroviral treatment guidelines. 2019.

34. Low A, Gavriilidis G, Larke N, B-Lajoie M-R, Drouin O, Stover J, et al. Incidence of opportunistic infections and the impact of antiretroviral therapy among HIV-infected adults in low- and middle-income countries: a systematic review and meta-analysis. Clin Infect Dis. 2016;62(12):1595-603. https://doi.org/10.1093/cid/ciw125.

35. Suthar AB, Lawn SD, del Amo J, Getahun H, Dye C, Sculier D, et al. Antiretroviral therapy for prevention of tuberculosis in adults with HIV: a 
systematic review and meta-analysis. PLoS Med. 2012;9(7):e1001270. https:// doi.org/10.1371/journal.pmed.1001270.

36. Wallgren A. The time-table of tuberculosis. Tubercle. 1948;29(11):245-51. https://doi.org/10.1016/S0041-3879(48)80033-4

37. Behr MA, Edelstein PH, Ramakrishnan L. Revisiting the timetable of tuberculosis. BMJ. 2018;362:k2738. https://doi.org/10.1136/bmj.k2738.

38. Houben RMGJ, Crampin AC, Ndhlovu R, Sonnenberg P, Godfrey-Faussett $P$, Haas $W H$, et al. Human immunodeficiency virus associated tuberculosis more often due to recent infection than reactivation of latent infection. Int J Tuberc Lung Dis. 2011;15(1):24-31.

39. Martinez L, Cords O, Horsburgh CR, Andrews JR. Pediatric TB Contact Studies Consortium. The risk of tuberculosis in children after close exposure: a systematic review and individual-participant meta-analysis. Lancet. 2020; 395(10228):973-84. https://doi.org/10.1016/S0140-6736(20)30166-5.

40. Fox GJ, Barry SE, Britton WJ, Marks GB. Contact investigation for tuberculosis: a systematic review and meta-analysis. Eur Respir J. 2013;41(1):140-56. https://doi.org/10.1183/09031936.00070812

41. Marais BJ, Gie RP, Schaaf HS, Hesseling AC, Obihara CC, Starke JJ, et al. The natural history of childhood intra-thoracic tuberculosis: a critical review of literature from the pre-chemotherapy era. Int J Tuberc Lung Dis. 2004;8(4): 392-402.

42. Tiemersma EW, van der Werf MJ, Borgdorff MW, Williams BG, Nagelkerke NJD. Natural history of tuberculosis: duration and fatality of untreated pulmonary tuberculosis in hiv negative patients: a systematic review. PLoS One. 2011;6(4):e17601. https://doi.org/10.1371/journal.pone.0017601.

43. Law S, Benedetti A, Oxlade O, Schwartzman K, Menzies D. Comparing costeffectiveness of standardised tuberculosis treatments given varying drug resistance. Eur Respir J. 2014;43(2):566-81. https://doi.org/10.1183/09031936. 00005613.

44. Zenner D, Beer N, Harris RJ, Lipman MC, Stagg HR, van der Werf MJ. Treatment of latent tuberculosis infection: an updated network meta-analysis. Ann Intern Med. 2017;167(4):248-55. https://doi.org/10.7326/M17-0609.

45. International Union Against Tuberculosis Committee on Prophylaxis. Efficacy of various durations of isoniazid preventive therapy for tuberculosis: five years of follow-up in the IUAT trial. International Union Against Tuberculosis Committee on Prophylaxis. Bull World Health Organ. 1982;60:555-64.

46. Mathema B, Andrews JR, Cohen T, Borgdorff MW, Behr M, Glynn JR, et al. Drivers of tuberculosis transmission. J Infect Dis. 2017;216(suppl_6):S644-53.

47. Villarino ME, Scott NA, Weis SE, Weiner M, Conde MB, Jones B, et al. Treatment for preventing tuberculosis in children and adolescents: a randomized clinical trial of a 3-month, 12-dose regimen of a combination of rifapentine and isoniazid. JAMA Pediatr. 2015;169(3):247-55. https://doi. org/10.1001/jamapediatrics.2014.3158.

48. Pease C, Hutton B, Yazdi F, Wolfe D, Hamel C, Quach P, et al. Efficacy and completion rates of rifapentine and isoniazid (3HP) compared to other treatment regimens for latent tuberculosis infection: a systematic review with network meta-analyses. BMC Infect Dis. 2017;17(1):265. https://doi.org/1 0.1186/s12879-017-2377-x.

49. Comstock GW. How much isoniazid is needed for prevention of tuberculosis among immunocompetent adults? Int J Tuberc Lung Dis. 1999; 3(10):847-50.

50. Kunkel A, Colijn C, Lipsitch M, Cohen T. How could preventive therapy affect the prevalence of drug resistance? Causes and consequences. Philos Trans R Soc Lond B Biol Sci. 2015;370:20140306.

51. Onozaki I, Law I, Sismanidis C, Zignol M, Glaziou P, Floyd K. National tuberculosis prevalence surveys in Asia, 1990-2012: an overview of results and lessons learned. Trop Med Int Health. 2015;20(9):1128-45. https://doi. org/10.1111/tmi.12534.

52. Ferebee SH, Mount FW. Tuberculosis morbidity in a controlled trial of the prophylactic use of isoniazid among household contacts. Am Rev Respir Dis. 1962;85:490-510. https://doi.org/10.1164/arrd.1962.85.4.490.

53. Debre R, Perdrizet S, Lotte A, Naveau M, Lert F. Isoniazid chemoprophylaxis of latent primary tuberculosis: in five trial centres in France from 1959 to 1969. Int J Epidemiol. 1973;2(2):153-60. https://doi.org/10.1093/ije/2.2.153.

54. Nolan CM, Aitken ML, Elarth AM, Anderson KM, Miller WT. Active tuberculosis after isoniazid chemoprophylaxis of Southeast Asian refugees. Am Rev Respir Dis. 1986;133(3):431-6. https://doi.org/10.1164/arrd.1 986.133.3.431.

55. Katz J, Kunofsky S, Damijonaitis V, Lafleur A, Caron T. Effect of isoniazid upon the reactivation of inactive tuberculosis; final report. Am Rev Respir Dis. 1965;91(3):345-50. https://doi.org/10.1164/arrd.1965.91.3.345.
56. Pape JW, Jean SS, Ho JL, Hafner A, Johnson WD. Effect of isoniazid prophylaxis on incidence of active tuberculosis and progression of HIV infection. Lancet. 1993;342(8866):268-72. https://doi.org/10.1016/0140-673 6(93)91817-6.

57. Guelar A, Gatell JM, Verdejo J, Podzamczer D, Lozano L, Aznar E, et al. A prospective study of the risk of tuberculosis among HIV-infected patients. AIDS. 1993;7(10):1345-9. https://doi.org/10.1097/00002030-199310000-00007.

58. Mwinga A, Hosp M, Godfrey-Faussett P, Quigley M, Mwaba P, Mugala BN, et al. Twice weekly tuberculosis preventive therapy in HIV infection in Zambia. AIDS. 1998;12(18):2447-57. https://doi.org/10.1097/00002030-19981 8000-00014.

59. Rangaka MX, Wilkinson RJ, Boulle A, Glynn JR, Fielding K, van Cutsem G, et al. Isoniazid plus antiretroviral therapy to prevent tuberculosis: a randomised double-blind, placebo-controlled trial. Lancet. 2014;384(9944): 682-90. https://doi.org/10.1016/S0140-6736(14)60162-8.

60. Hong Kong Chest Service, Tuberculosis Research Centre Madras, and British Medical Research Council. A controlled trial of 2-month, 3-month, and $12-$ month regimens of chemotherapy for sputum-smear-negative pulmonary tuberculosis. Results at 60 months. Am Rev Respir Dis. 1984;130:23-8.

61. Comstock GW, Ferebee SH, Hammes LM. A controlled trial of communitywide isoniazid prophylaxis in Alaska. Am Rev Respir Dis. 1967;95(6):935-43. https://doi.org/10.1164/arrd.1967.95.6.935.

62. Pamra SP, Mathur GP. Effects of chemoprophylaxis on minimal pulmonary tuberculosis lesions of doubtful activity. Bull World Health Organ. 1971;45(5): 593-602.

63. Dean AS, Zignol M, Cabibbe AM, Falzon D, Glaziou P, Cirillo DM, et al. Prevalence and genetic profiles of isoniazid resistance in tuberculosis patients: a multicountry analysis of cross-sectional data. PLoS Med. 2020; 17(1):e1003008. https://doi.org/10.1371/journal.pmed.1003008.

64. Sterling TR, Villarino ME, Borisov AS, Shang N, Gordin F, Bliven-Sizemore E, et al. Three months of rifapentine and isoniazid for latent tuberculosis infection. N Engl J Med. 2011;365(23):2155-66. https://doi.org/10.1056/ NEJMoa1104875.

65. Canetti G. Present aspects of bacterial resistance in tuberculosis. Am Rev Respir Dis. 1965;92(5):687-703. https://doi.org/10.1164/arrd.1965.92.5.687.

66. Kayigire XA, Friedrich SO, van der Merwe L, Diacon AH. Acquisition of rifampin resistance in pulmonary tuberculosis. Antimicrob Agents Chemother. 2017;61(4). https://doi.org/10.1128/AAC.02220-16.

67. Gillespie $\mathrm{SH}$. Evolution of drug resistance in mycobacterium tuberculosis: clinical and molecular perspective. Antimicrob Agents Chemother. 2002; 46(2):267-74. https://doi.org/10.1128/AAC.46.2.267-274.2002.

68. World Health Organization. WHO treatment guidelines for isoniazid-resistant tuberculosis: supplement to the WHO treatment guidelines for drugresistant tuberculosis. Geneva: WHO; 2018.

69. National Institute for Communicable Diseases D of the NHLS. South African tuberculosis drug resistance survey. 2016, 2012-14.

70. Mvelase NR, Balakrishna Y, Lutchminarain K, Mlisana K. Evolving rifampicin and isoniazid mono-resistance in a high multidrug-resistant and extensively drug-resistant tuberculosis region: a retrospective data analysis. BMJ Open. 2019;9(11):e031663. https://doi.org/10.1136/bmjopen-2019-031663.

71. Ayaz A, Hasan Z, Jafri S, Inayat R, Mangi R, Channa AA, et al. Characterizing Mycobacterium tuberculosis isolates from Karachi, Pakistan: drug resistance and genotypes. Int J Infect Dis. 2012;16(4):e303-9. https://doi.org/10.1016/j. ijid.2011.12.015.

72. Ministry of Health and Family Welfare, World Health Organization India, DOTS, National Health Mission, USAID. Report of the First National Anti TB Drug Resistance Survey, India 2014-2016.

73. World Health Organization. Chest radiography in tuberculosis detection. World Health Organization; 2016.

74. Horne DJ, Kohli M, Zifodya JS, Schiller I, Dendukuri N, Tollefson D, et al. Xpert MTB/RIF and Xpert MTB/RIF Ultra for pulmonary tuberculosis and rifampicin resistance in adults. Cochrane Database Syst Rev. 2019;6: CD009593. https://doi.org/10.1002/14651858.CD009593.pub4.

75. Drain PK, Hong T, Krows M, Govere S, Thulare H, Wallis CL, et al. Validation of clinic-based cryptococcal antigen lateral flow assay screening in HIVinfected adults in South Africa. Sci Rep. 2019;9(1):2687. https://doi.org/10.103 8/s41598-018-37478-7.

76. Bajema KL, Bassett IV, Coleman SM, Ross D, Freedberg KA, Wald A, et al. Subclinical tuberculosis among adults with HIV: clinical features and outcomes in a South African cohort. BMC Infect Dis. 2019;19(1):14. https:// doi.org/10.1186/s12879-018-3614-7. 
77. Oni T, Burke R, Tsekela R, Bangani N, Seldon R, Gideon HP, et al. High prevalence of subclinical tuberculosis in HIV-1-infected persons without advanced immunodeficiency: implications for TB screening. Thorax. 2011; 66(8):669-73. https://doi.org/10.1136/thx.2011.160168.

78. Flynn AG, Aiona K, Haas MK, Reves R, Belknap R. Clinical characteristics of active tuberculosis diagnosed after starting treatment for latent tuberculosis infection. Clin Infect Dis. 2020;71(5):1320-3. https://doi.org/10.1093/cid/ciz1157.

79. Datta B, Prakash A, Ford D, Tripathy JP, Goyal P, Singh S, et al. Implementing upfront mobile digital chest $\mathrm{x}$-ray for tuberculosis diagnosis in Indiafeasibility and benefits. Trans R Soc Trop Med Hyg. 2020;114(7):499-505. https://doi.org/10.1093/trstmh/traa015.

80. Moodley N, Velen K, Saimen A, Zakhura N, Churchyard G, Charalambous S. Digital chest radiography enhances screening efficiency for pulmonary tuberculosis in primary health clinics, South Africa. Clin Infect Dis. 2021: ciab644. https://doi.org/10.1093/cid/ciab644

81. MacPherson P, Webb EL, Kamchedzera W, Joekes E, Mjoli G, Lalloo DG, et al. Computer-aided X-ray screening for tuberculosis and HIV testing among adults with cough in Malawi (the PROSPECT study): A randomised trial and cost-effectiveness analysis. PLoS Med. 2021;18(9):e1003752. https://doi.org/1 0.1371/journal.pmed.1003752.

82. Mills HL, Cohen T, Colijn C. Community-wide isoniazid preventive therapy drives drug-resistant tuberculosis: a model-based analysis. Sci Transl Med. 2013:5:180ra49.

83. Fox GJ, Oxlade O, Menzies D. Fluoroquinolone therapy for the prevention of multidrug-resistant tuberculosis in contacts. a cost-effectiveness analysis. Am J Respir Crit Care Med. 2015;192(2):229-37. https://doi.org/10.1164/rccm.201 501-00690C

84. Rockwood N, Sirgel F, Streicher E, Warren R, Meintjes G, Wilkinson RJ. Low frequency of acquired isoniazid and rifampicin resistance in rifampicinsusceptible pulmonary tuberculosis in a setting of high HIV-1 infection and tuberculosis coprevalence. J Infect Dis. 2017;216(6):632-40. https://doi.org/1 0.1093/infdis/jix337.

85. Campbell JR, Al-Jahdali H, Bah B, Belo M, Cook VJ, Long R, et al. Safety and efficacy of rifampin or isoniazid among people with mycobacterium tuberculosis infection and living with HIV or other health conditions: posthoc analysis of two randomized trials. Clin Infect Dis. 2020:ciaa1169.

\section{Publisher's Note}

Springer Nature remains neutral with regard to jurisdictional claims in published maps and institutional affiliations.

Ready to submit your research? Choose BMC and benefit from:

- fast, convenient online submission

- thorough peer review by experienced researchers in your field

- rapid publication on acceptance

- support for research data, including large and complex data types

- gold Open Access which fosters wider collaboration and increased citations

- maximum visibility for your research: over $100 \mathrm{M}$ website views per year

At $\mathrm{BMC}$, research is always in progress.

Learn more biomedcentral.com/submissions 